\title{
Effects of intrauterine exposures to polychlorinated biphenyls, methylmercury, and lead on birth weight in Japanese male and female newborns
}

Nozomi Tatsuta ${ }^{1,7}$, Naoyuki Kurokawa ${ }^{2}, K_{\text {Kunihiko Nakai }}^{1,7^{*}}$, Keita Suzuki ${ }^{3}$, Miyuki Iwai-Shimada ${ }^{4}$, Katsuyuki Murata ${ }^{5}$ and Hiroshi Satoh ${ }^{6}$

\begin{abstract}
Background: The effects of prenatal exposures to polychlorinated biphenyls (PCBs), methylmercury, and lead on birth weight remain disputable. The aim of this study was to investigate whether these chemicals affect birth weight of Japanese newborns, with special emphasis on determining whether these effects differ between males and females.

Methods: The subjects from Tohoku Study of Child Development, which was designed to examine the developmental effects of prenatal exposures to such hazardous chemicals, were 489 mother-newborn pairs with complete data including smoking habit during pregnancy.

Results: The mean birth weight of all newborns was 3083 (range, 2412-4240) g. The median values of biomarkers in cord blood were 46.0 (5th and 95th percentiles, 18.6-113.8) ng/g-lipid for total PCBs, 10.1 (4.3-22.4) ng/g for total mercury (THg), and $1.0(0.6-1.7) \mu \mathrm{g} / \mathrm{dL}$ for lead. The birth weight was significantly heavier in the 252 male newborns than in the 237 female ones. A negative association between total PCBs and birth weight was observed in both male and female newborns, even after adjusting for possible confounders. However, a negative association of THg with birth weight was found only in the male newborns. There was no significant relationship between lead and birth weight in both groups.

Conclusion: Birth weight appears to be affected by prenatal PCB exposure in Japanese male and female newborns, and the effect of methylmercury exposure on male fetal growth may be stronger than that for females. This implication is that the effects on fetal growth should be assessed in males and females separately.
\end{abstract}

Keywords: Polychlorinated biphenyls, Methylmercury, Lead, Birth weight, Sex difference

\section{Background}

Since polychlorinated biphenyls (PCBs) and methylmercury that are environmentally persistent toxicants cross the placenta, they may affect child development. Prenatal lead exposure seems to result in low birth weight [1-6]. However, the effects of PCBs and methylmercury on fetal growth remain controversial [7]: Some studies, performed

\footnotetext{
* Correspondence: nakaik@med.tohoku.ac.jp

${ }^{1}$ Development and Environmental Medicine, Tohoku University Graduate School of Medicine, Sendai, Japan

72-1 Seiryo-machi, Aoba-ku, Sendai, Miyagi 980-8575, Japan

Full list of author information is available at the end of the article
}

in developed countries, reported adverse effects of prenatal PCB exposure on birth weight [8-11]; by contrast, one study showed a positive association between them [12]. Others failed to find such a significant association [13-17]. Likewise, Foldspang and Hansen reported that high maternal and offspring methylmercury concentrations were associated with low birth weight [18], but other researchers did not present a significant association between the exposure and outcome [5, 19-21]. Apart from prenatal exposures via fish and seafood intake, the children of heavy and moderate smokers during pregnancy have a higher rate of being small for gestational age (SGA) 
than those of non-smokers [22]. If the number of cigarettes smoked and passive smoking during pregnancy were not examined in a study [8], absence of the principal cause would confuse a result derived from such toxic substances. Low birth weight is known to be associated with several chronic diseases in adults, including diabetes mellitus and hypertension [23]. For the prevention of adult diseases, therefore, it is crucial to confirm which pollutants affect fetal growth.

In recent years, the exposure levels of environmental pollutants such as PCBs and lead are low in developed countries [24, 25], predicting that the range of exposure (i.e., difference between the minimum and maximum) may not be wide enough to detect a statistically significant dose-response relationship. In this case, use of concurrent exposure model will be desirable for considering the interactive effect of potential substances other than the concerned one, even though the exposure levels were not so high. In fact, essential nutrients such as $n$ - 3 polyunsaturated fatty acids (PUFAs) masked the effects of methylmercury $[26,27]$. Also, two previous studies demonstrated the association between maternal PCB concentrations and low birth weight only in male newborns $[28,29]$, hypothesizing that male fetuses may be more vulnerable to such toxicants than female ones. Thus, careful selection of study subjects, exposure markers and possible confounders is sought when examining the complicated link between prenatal low-level exposures and fetal growth.

We have been performing a prospective birth cohort study (i.e., Tohoku Study of Child Development, TSCD), focusing both on the potential risks and benefits of fish eating during pregnancy to investigate the effects of toxic chemicals on child development in Japan [30-33]. In this study, we investigated the impacts of PCBs, methylmercury and lead on birth weight in Japanese newborns, with special emphasis on determining whether the effects differed between males and females. At the same time, we reconsidered some confounders that may mislead our result in data analysis.

\section{Methods}

\section{Study design and subjects}

The detailed study design and protocol of TSCD have been already described in our previous paper [34]. The research field was comprised of two areas, an urban area and a coastal area in the northeast region of Japan, but the subjects recruited at obstetrical wards of two hospitals in the urban area (i.e., Sendai City, Miyagi) were employed in this study because the PCB concentrations in cord blood were determined only in that area. To establish an optimal study population, the eligibility criteria included a singleton pregnancy, Japanese as the mother tongue, neonates born at term (36-42 weeks of gestation) with birth weight of more than $2400 \mathrm{~g}$, and no congenital anomalies or diseases. Information about pregnancy, delivery and the characteristics of infants at birth was obtained from medical records. All procedures of this study were approved by the Medical Ethics Committee of the Tohoku University Graduate School of Medicine.

We enrolled 687 women in this study with their written informed consent, in accordance with the Declaration of Helsinki of 1964 as revised in 2000; and, 599 mothernewborn pairs were registered by September 2003 (participation rate, $87.2 \%)$. Of them, 489 pairs with complete information on the PCBs, mercury and lead concentrations in cord blood, birth weight, and possible confounders such as gestational age and seafood intake were used in the present study.

\section{Exposure markers}

Umbilical cord blood was collected into a clean bottle immediately after birth. The samples were frozen at $-80{ }^{\circ} \mathrm{C}$ until analysis. All 209 PCB congeners were analyzed using high-resolution gas chromatography/high-resolution mass spectrometry with the isotope dilution method. The laboratory analytical methods and quality control procedures have been described elsewhere [35]. All sample analyses were performed by IDEA Consultants, Inc. (Tokyo, Japan) and Shimadzu Techno-Research, Inc. (Kyoto, Japan). The quality of PCB analyses in the two laboratories was validated using an external quality assurance program, the German external assurance scheme at IDEA Consultants, Inc., and that of the Fukuoka Institute of Health and Environmental Sciences at Shimadzu Techno-Research, Inc. Accuracy was ensured using a reference serum sample for quality control; the International Union of Pure and Applied Chemistry No.28, 52, 101, 138, 153, 180 of PCB congeners were determined to be $0.310,0.162,0.150,0.220$, 0.217 , and $0.300 \mu \mathrm{g} / \mathrm{L}$, as compared to the reference value (tolerance range in parenthesis) of 0.284 (0.181-0.388), 0.162 (0.102-0.222), $0.172(0.126-0.218), 0.242$ (0.174$0.310), 0.217$ (0.152-0.281), and $0.307(0.222-0.392) \mu \mathrm{g} / \mathrm{L}$, respectively. The PCB data from two laboratories showed no significant difference by paired $t$ test $(t=-2.572, P=$ 0.062) and a high Pearson product-moment correlation coefficient $(r=0.869)$. The calculated limit of detection (LOD) was $0.03 \mathrm{pg} / \mathrm{g}$-wet, which was identified by the signal-to-noise ratio. The amounts of congeners below the LOD were set at zero. We used the lipid basis for the sum concentration of the all measured PCB congeners ( $\Sigma \mathrm{PCB})$, expressed as ng/g-lipid [36].

Total mercury (THg) and lead concentrations in whole cord blood were analyzed by IDEA Consultants, Inc. (Tokyo, Japan), using cold vapor atomic absorption spectrometry for $\mathrm{THg}$ and inductively coupled plasma mass spectrometry for lead [30]. Maternal hair samples were also obtained from the back of the head near the occipital protuberance 2 days after delivery, and the THg levels 
in 3-cm hair close to the scalp were measured by cold vapor atomic absorption spectrophotometry [30]. The data quality for $\mathrm{THg}$ and lead concentrations was validated using external quality assurance programs [37].

\section{Possible confounders}

Information about pregnancy, delivery and characteristics of newborns such as maternal height and body weight before pregnancy, gestational age (weeks), delivery type (spontaneous/Caesarean section or vacuum extraction), birth weight and parity (first child or not), was extracted from medical records. The body mass index (BMI, $\mathrm{kg} / \mathrm{m}^{2}$ ) before pregnancy was calculated from the height and body weight. We obtained information about demographics and smoking and drinking habits during pregnancy (presence/absence) from a questionnaire 4 days after delivery. At the same time, maternal intake of fish/seafood during pregnancy also was assessed using a food frequency questionnaire that was administered by trained interviewers.

\section{Data analysis}

Sex differences in basal characteristics and exposure levels were analyzed by Student $t$ test, Mann-Whitney $U$ test or Fisher exact test. The $\Sigma \mathrm{PCB}, \mathrm{THg}$, and lead concentrations in cord blood and fish/seafood intake were logarithmically transformed because of the skewed distribution. Although the $\Sigma$ PCB and 2,2,4,4,5,5'-hexachlorobiphenyl (PCB-153) of major PCB congener measured by two laboratories seemed to be comparable as mentioned above, they were used after the adjustment for the laboratory by using multiple regression analysis. Pearson product-moment correlation coefficients were used to test the relationships between either birth weight or body weight gain during pregnancy and the relating indicators including exposure biomarkers. Multiple regression analysis was employed to adjust for gestational age, parity, BMI before pregnancy, smoking/drinking habits during pregnancy, and fish/seafood intake, whereas parity showed a strong relation to PCBs, i.e., the first child had higher-level PCBs than the other one [35, 38]. In addition, the impact of collinearity among $\mathrm{\Sigma PCB}, \mathrm{THg}$, and fish/seafood intake was measured by the variance inflation factor (VIF): The VIF was calculated for each predictor by doing a linear regression of that predictor on all the other predictors, i.e., $\mathrm{VIF}=1 /\left(1-R^{2}\right)$, where $R$ is the multiple correlation coefficient; and, a predictor with VIF $>10$ is considered as an indicative of serious collinearity [39]. All analyses, with two-sided $p$ values, were performed using SPSS Ver. 23.0 (SPSS Japan, Tokyo) and the significance level was set at $5 \%$.

\section{Results}

The mean birth weight of 489 newborns was 3083 (range, 2412-4240) g, and the gestational age was $39.5 \pm 1.3$ (SD) weeks. The median values of biomarkers in cord blood were 46.0 (5th and 95th percentiles, 18.6 - 113.8) ng/glipid for $\Sigma \mathrm{PCB}, 10.1(4.3-22.4) \mathrm{ng} / \mathrm{g}$ for $\mathrm{THg}$, and 1.0 $(0.6-1.7) \mu \mathrm{g} / \mathrm{dL}$ for lead. The median $\Sigma \mathrm{PCB}$ concentration was $0.122(0.050-0.332) \mathrm{ng} / \mathrm{g}$-wet and the correlation coefficient $(r)$ between the wet-base and lipid-base was 0.892 $(p<0.001)$. The median $\mathrm{THg}$ concentration in maternal hair was $2.0(0.9-4.4) \mu \mathrm{g} / \mathrm{g}$ and the $r$ between those in hair and cord blood was $0.841(p<0.001)$. Since birth weight differed significantly between 252 male and 237 female newborns as shown in Table 1, the following analyses were carried out for the male and female newborns separately.

Table 2 represents correlations between either birth weight or body weight gain during pregnancy and the related indicators. In the 489 mother-newborn pairs, gestational age, BMI before pregnancy, and body weight gain during pregnancy showed significant correlations with birth weight; similarly, maternal age, gestational age, and BMI had significant correlations with body weight gain during pregnancy. Notably, birth weight and body weight gain were negatively correlated with $\mathrm{PCCB}$ and PCB-153 in the male and female newborns, and $\mathrm{THg}$ was inversely related to birth weight only in the male newborns.

Relations of prenatal biomarkers to birth weight in the mother-newborn pairs are listed in Table 3. In this table, although parity was significantly associated with birth weight in the total newborns, it was not so in the male or female newborns. In adding two interactive variables of $(\operatorname{sex}) \times($ $\Sigma \mathrm{PCB})$ and $(\mathrm{sex}) \times(\mathrm{THg})$ in independent variables of the total newborns, the two variables were not significantly related to birth weight ( $p=0.983$ and $p=0.373$, respectively) but the significance of other variables presented in Table 3 remained unchanged.

As shown in Table 3, lower birth weight was significantly associated with $\triangle \mathrm{PCB}$ in the male and female newborns, but also with THg only in the male ones. On the other hand, there was no significant association between cordblood lead and birth weight for either sex. Even when adding body weight gain during pregnancy to independent variables of the multiple regression models, the significance of $\Sigma \mathrm{PCB}$ and THg was almost the same as in Table 3. Concerning the collinearity among exposure markers of 489 newborns, the correlation coefficients were $0.171(p<$ $0.001)$ for $\Sigma \mathrm{PCB}$ and THg, $0.069(p=0.128)$ for $\Sigma \mathrm{PCB}$ and fish/seafood intake, and $0.239(p<0.001)$ for THg and fish/ seafood intake; and, the VIFs for $\mathrm{EPCB}, \mathrm{THg}$, and fish/seafood intake were 1.045, 1.097, and 1.078, respectively.

\section{Discussion}

Given the concurrent exposure model of environmental pollutants, the principal findings of our study were that birth weight was associated with $\Sigma \mathrm{PCB}$ concentrations in the male and female newborns, and also with $\mathrm{THg}$ concentrations in the male ones. However, the significant relation to lead was not seen, probably not only because of 
Table 1 Basal characteristics and exposure levels in 489 mother-baby pairs

\begin{tabular}{|c|c|c|c|}
\hline & Male newborns $(n=252)$ & Female newborns $(n=237)$ & $p$ value $^{a}$ \\
\hline & $\begin{array}{l}\text { Mean } \pm \text { SD or median and the } \\
5-95 \text { percentiles (or number } \\
\text { and } \% \text { ) in parenthesis }\end{array}$ & $\begin{array}{l}\text { Mean } \pm \text { SD or median and the } \\
5-95 \text { percentiles (or number } \\
\text { and } \% \text { ) in parenthesis }\end{array}$ & \\
\hline Maternal characteristics & & & \\
\hline Maternal age (years) & $31.5 \pm 4.3$ & $31.3 \pm 4.4$ & 0.497 \\
\hline Body weight before pregnancy $(\mathrm{kg})$ & $53.1 \pm 7.4$ & $52.6 \pm 8.4$ & 0.511 \\
\hline Body mass index before pregnancy $\left(\mathrm{kg} / \mathrm{m}^{2}\right)$ & $21.0 \pm 2.4$ & $20.9 \pm 3.3$ & 0.906 \\
\hline Body weight gain during pregnancy (kg) & $9.6 \pm 3.7$ & $9.8 \pm 3.6$ & 0.584 \\
\hline Fish/seafood intake during pregnancy (g/day) & $51.6(13.1-109.2)$ & $53.6(12.2-131.4)$ & 0.201 \\
\hline Smoking habit during pregnancy (smokers, \%) & $17(6.7)$ & $20(8.4)$ & 0.499 \\
\hline Drinking habit during pregnancy (drinkers, \%) & $82(32.5)$ & $73(30.8)$ & 0.698 \\
\hline Delivery type (spontaneous, \%) & $176(69.8)$ & $178(75.1)$ & 0.225 \\
\hline Newborn characteristics & & & \\
\hline Gestational age (weeks) & $39.5 \pm 1.3$ & $39.6 \pm 1.2$ & 0.516 \\
\hline Birth weight (g) & $3126 \pm 353$ & $3036 \pm 314$ & 0.003 \\
\hline Parity (first-born children, \%) & $133(52.8)$ & $123(51.9)$ & 0.857 \\
\hline Biomarkers in cord blood & & & \\
\hline Total PCBs (ng/g-lipid) ${ }^{b}$ & $49.4(16.3-118.6)$ & $44.6(19.6-107.5)$ & 0.170 \\
\hline PCB-153 (ng/g-lipid) ${ }^{b}$ & $10.6(3.2-27.9)$ & $9.7(3.9-23.4)$ & 0.243 \\
\hline Total mercury (ng/g) & $10.2(4.5-23.8)$ & $9.9(4.0-21.4)$ & 0.669 \\
\hline Lead $(\mu \mathrm{g} / \mathrm{dL})$ & $1.0(0.6-1.7)$ & $1.0(0.5-1.7)$ & 0.252 \\
\hline
\end{tabular}

${ }^{a}$ Student $t$ test, Mann-Whitney $U$ test, and Fisher exact test were used for significant difference test

${ }^{\mathrm{b}}$ These data were used following adjusting for the laboratory

low lead levels but also the extremely narrow range of lead exposure, as compared to the values reported previously [2-6]; whereas, Taylor and coworkers could not find any evidence suggesting a dose-response relationship either in 4190 births (median of maternal blood lead, $3.40 \mu \mathrm{g} / \mathrm{dL}$; range, $0.20-19.14 \mu \mathrm{g} / \mathrm{dL}$ ) [40]. In addition, no evidence of multicollinearity problem among $\mathrm{\Sigma PCB}, \mathrm{THg}$, and fish/ seafood intake or of interaction between sex and toxic substances on birth weight was suggested, because all the VIFs were less than 2 in the present study [39]. Thus, a concurrent exposure model appears to be important for the assessment of the effect on fetal growth/SGA, whereas this model did not include interactive variables between these chemicals. Otherwise, the effect of prenatal exposures to a plural pollutant at low levels may be underestimated or ignored.

In the current study, there was a significant negative relationship between cord-blood $\Sigma \mathrm{PCB}$ and birth weight in the 489 newborns, along with in each group of the male and female ones. This is consistent with results of many reports [8-11, 41-43]. Two previous studies observed the negative association only in male newborns [28, 29], and Yamashita and Hayashi confirmed it only in female newborns [44]. However, some reports could not find such a significant association [13-17]. At least, all studies using cord blood as a biological specimen demonstrated the significant association; that is, it may be preferable to use the more direct specimen when compared to maternal blood or milk, inasmuch as maternal and umbilical-cord concentrations in red blood cells do not show a significant correlation for several chemical substances [45]. Taken together, our data support the idea that PCBs can affect fetal growth. The ultimate way to protect fetuses against the harmful effect of PCBs, therefore, is for girls and women not to eat specific fish/marine mammals containing high-level PCBs, like whale blubber, until they have given birth as recommended in dietary advisories of the Faroe Islands [46].

A significant association of cord-blood $\mathrm{THg}$ with low birth weight was observed in the male newborns, but not in the female ones, while the impact of methylmercury did not seem to be stronger than that of PCBs judging from $\beta$ values of Table 3. This finding is similar to that reported by Foldspang and Hansen [18], who examined 376 mothers living in Greenland and demonstrated a negative effect of dietary methylmercury on intrauterine growth. By contrast, Obi and coworkers reported that cord-blood mercury was positively associated with birth weight and length [47], which may have been due to the fact that their THg levels were extremely low (median, $4.9 \mu \mathrm{g} / \mathrm{L}$ ) and their data were unadjusted for any confounders. However, some studies did not detect any significant relationships between the exposure and 
Table 2 Correlation coefficients $(r)$ between birth weight and gestational weight gain and the relating indicators

\begin{tabular}{|c|c|c|c|c|}
\hline & \multicolumn{2}{|c|}{ Birth weight } & \multicolumn{2}{|c|}{ Body weight gain during pregnancy } \\
\hline & $r$ & $p$ value & $r$ & $p$ value \\
\hline \multicolumn{5}{|l|}{252 Male newborns } \\
\hline Gestational age & 0.413 & $<0.001$ & 0.145 & 0.021 \\
\hline Maternal age & -0.022 & 0.722 & -0.278 & $<0.001$ \\
\hline Body mass index before pregnancy & 0.175 & 0.005 & 0.059 & 0.354 \\
\hline Body weight gain during pregnancy & 0.200 & 0.001 & - & \\
\hline Fish/seafood intake & 0.045 & 0.473 & 0.029 & 0.651 \\
\hline Total PCBs in cord blood ${ }^{a, b}$ & -0.252 & $<0.001$ & -0.334 & $<0.001$ \\
\hline PCB-153 in cord blood ${ }^{a, b}$ & -0.247 & $<0.001$ & -0.325 & $<0.001$ \\
\hline Total mercury in cord blood ${ }^{\mathrm{b}}$ & -0.130 & 0.039 & -0.007 & 0.917 \\
\hline Lead in cord blood ${ }^{\mathrm{b}}$ & -0.025 & 0.698 & 0.037 & 0.560 \\
\hline \multicolumn{5}{|l|}{237 Female newborns } \\
\hline Gestational age & 0.311 & $<0.001$ & 0.116 & 0.074 \\
\hline Maternal age & 0.081 & 0.212 & -0.127 & 0.050 \\
\hline Body mass index before pregnancy & 0.176 & 0.006 & -0.245 & $<0.001$ \\
\hline Body weight gain during pregnancy & 0.251 & 0.004 & - & \\
\hline Fish/seafood intake & 0.048 & 0.465 & -0.010 & 0.874 \\
\hline Total PCBs in cord blood ${ }^{a, b}$ & -0.170 & 0.009 & -0.270 & $<0.001$ \\
\hline PCB-153 in cord blood ${ }^{a, b}$ & -0.179 & 0.006 & -0.264 & $<0.001$ \\
\hline Total mercury in cord blood ${ }^{b}$ & -0.023 & 0.720 & 0.039 & 0.555 \\
\hline Lead in cord blood ${ }^{\mathrm{b}}$ & -0.030 & 0.642 & 0.126 & 0.053 \\
\hline \multicolumn{5}{|l|}{ Total newborns } \\
\hline Gestational age & 0.361 & $<0.001$ & 0.133 & 0.003 \\
\hline Maternal age & 0.029 & 0.519 & -0.208 & $<0.001$ \\
\hline Body mass index before pregnancy & 0.171 & $<0.001$ & -0.103 & 0.022 \\
\hline Body weight gain during pregnancy & 0.190 & $<0.001$ & - & \\
\hline Fish/seafood intake & 0.043 & 0.348 & 0.009 & 0.843 \\
\hline Total PCBs in cord blood ${ }^{a, b}$ & -0.207 & $<0.001$ & -0.307 & $<0.001$ \\
\hline PCB-153 in cord blood ${ }^{a, b}$ & -0.209 & $<0.001$ & -0.299 & $<0.001$ \\
\hline Total mercury in cord blood ${ }^{b}$ & -0.074 & 0.100 & 0.014 & 0.763 \\
\hline Lead in cord blood ${ }^{b}$ & -0.022 & 0.635 & 0.078 & 0.086 \\
\hline
\end{tabular}

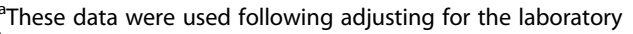

${ }^{\mathrm{b}} \mathrm{All}$ biomarkers in cord blood and seafood intake were logarithmically transformed

birth outcomes $[5,19-21]$. If these analyses were done for males and females separately, they might have discovered a significant association. Thus, male birth weight appears to have been affected by prenatal methylmercury exposure at relatively low levels (median, $10.2 \mathrm{ng} / \mathrm{g}$ in cord blood). In fact, when the methylmercury pollution in Minamata, Japan, was most severe (i.e., in 1955-1959), decreases in male births were observed in the overall city population, in fishermen, and in maternal Minamata disease patients, and an increase in the proportion of male stillborn fetuses was seen [48]. In other words, male fetuses are suggested to be more susceptible to methylmercury than female counterparts. Sex difference should be kept in mind when assessing reproductive toxicants.

In examining the relationships between environmental pollutants and fetal growth, gestational weight gain is frequently used as a possible confounder [12, 20, 43]. However, body weight gain during pregnancy was significantly correlated with birth weight (Table 2), and it showed close relations to the $\Sigma$ PCB and PCB-153, as well as gestational age, maternal age, and BMI before pregnancy, which implies that birth weight and gestational weight gain together are outcome variables originating from intrauterine PCB exposure. Verner and coworkers noted that gestational weight gain is an imprecise measure of the increased 
Table 3 Relations of prenatal biomarkers and confounders to birth weight: results of multiple regression analysis ${ }^{\mathrm{a}}$

\begin{tabular}{|c|c|c|c|c|c|c|}
\hline & \multicolumn{2}{|l|}{252 Male newborns } & \multicolumn{2}{|l|}{237 Female newborns } & \multicolumn{2}{|l|}{ Total newborns } \\
\hline & $\begin{array}{l}\text { Standardized regression } \\
\text { coefficient, } \beta\end{array}$ & $p$ value & $\begin{array}{l}\text { Standardized regression } \\
\text { coefficient, } \beta\end{array}$ & $p$ value & $\begin{array}{l}\text { Standardized regression } \\
\text { coefficient, } \beta\end{array}$ & $p$ value \\
\hline Total PCBs in cord blood & -0.171 & 0.004 & -0.166 & 0.009 & -0.161 & $<0.001$ \\
\hline Total mercury in cord blood & -0.120 & 0.042 & -0.042 & 0.499 & -0.078 & 0.061 \\
\hline Lead in cord blood & 0.023 & 0.692 & -0.039 & 0.513 & -0.011 & 0.784 \\
\hline \multicolumn{7}{|l|}{ Possible confounders } \\
\hline Gestational age & 0.397 & $<0.001$ & 0.373 & $<0.001$ & 0.383 & $<0.001$ \\
\hline Parity & 0.075 & 0.201 & 0.102 & 0.116 & 0.093 & 0.030 \\
\hline $\begin{array}{l}\text { Body mass index before } \\
\text { pregnancy }\end{array}$ & 0.143 & 0.012 & 0.227 & $<0.001$ & 0.180 & $<0.001$ \\
\hline Smoking during pregnancy & -0.066 & 0.237 & 0.080 & 0.185 & 0.006 & 0.889 \\
\hline Drinking during pregnancy & 0.001 & 0.986 & 0.019 & 0.756 & 0.010 & 0.812 \\
\hline Fish/seafood intake & 0.080 & 0.168 & 0.067 & 0.288 & 0.069 & 0.099 \\
\hline Child sex & - & - & - & - & 0.159 & $<0.001$ \\
\hline Contribution rate, $R^{2}$ & 0.229 & $<0.001$ & 0.204 & $<0.001$ & 0.239 & $<0.001$ \\
\hline
\end{tabular}

${ }^{a}$ Total PCBs was used following adjusting for the laboratory, and all biomarkers in cord blood and fish/seafood intake were logarithmically transformed $R$ indicates the multiple correlation coefficient

maternal lipid compartment during pregnancy [43]. A significant association of parity with PCB concentrations is also well-known [35]. In fact, the addition of either gestational weight gain or parity in multiple regression analysis did not change our results when PCB levels existed (Table 3). Accordingly, it is suggested that superficial confounders had better to be excluded from explanatory variables of birth size to avoid misleading or overadjustment.

There may have been some limitations in this study. Although n-3 PUFAs are essential for normal brain development, we could not determine the levels because of the limited amount of cord blood available. Instead of $n$ 3 PUFAs, we used fish/seafood intake in the data analysis, whereas it is thought to indicate the exposure levels of both beneficial nutrients and toxic substances such as methylmercury and dioxin-like PCBs [27, 49]. Other persistent organic pollutants such as dioxin-like PCBs, polychlorinated dibenzo-p-dioxines, and polychlorinated dibenzofurans, were not analyzed in this study but a significant correlation between dioxin-like PCBs and $\Sigma$ PCB $(r=0.91)$ was observed in 49 samples of our participants [35]. Likewise, smoking habit during pregnancy was employed as a substitute for the number of cigarettes smoked. There is also a paper describing that birth weight may decrease at high intake levels of marine fats [50], but neither fish/seafood intake nor smoking habit was significantly related to birth weight in the multiple regression analysis as shown in Table 3. As mentioned above, the $\Sigma$ PCB concentrations in cord blood were determined at two different laboratories, but these values were used following adjustment for the institute. Thus, our data appear not to have been heavily influenced by confounders or measurement bias.

\section{Conclusion}

Birth weight in both male and female newborns appears to be affected by maternal PCB exposure. Intrauterine methylmercury at low levels may also affect male birth weight. Concerning the effect on fetal growth, further studies are necessary to clarify the toxic mechanism of such chemicals, and also to scrutinize sex difference in the outcomes attributable to environmental pollutants other than PCBs and methylmercury.

\section{Abbreviations}

BMI: Body mass index; LOD: Limit of detection; n-3 PUFAs: Polyunsaturated fatty acids; PCBs: Polychlorinated biphenyls; SGA: Small for gestational age; THg: Total mercury; TSCD: Tohoku Study of Child Development; VIF: Variance inflation factor

\section{Acknowledgments}

We thank all the families for their participation in the cohort study. We would like to acknowledge Drs. Tomoko Sugawara-Oka, Kozue YaginumaSakurai, Takashi Ohba, Satomi Kameo, and Tomoyuki Nakamura, who were members of the TSCD. This research was funded by the Japan Ministry of Health, Labor and Welfare, the Ministry of the Environment, and the Ministry of Education, Culture, Sports, Science and Technology (Grant-in-Aid for Young Scientists $[\mathrm{B}])$.

\section{Funding}

This research was funded by the Japan Ministry of Health, Labor and Welfare, the Ministry of the Environment, and the Ministry of Education, Culture, Sports, Science and Technology (Grant-in-Aid for Young Scientists [B]).

\section{Availability of data and materials}

It is not possible to share the raw research data publicly since data privacy could be compromised. However, the raw data are available with the corresponding author, and any researcher interested to gain access to the raw data can address his/her request to the corresponding author at the contact information mentioned in the manuscript. All data generated or analyzed during this study are included in this published article and its supplementary information. 


\section{Authors' contribution}

NT participated in the analysis and interpretation of the data, drafted the manuscript and approved the version as submitted. NK participated in the design of the study and performed the statistical analysis. KN participated in the conception, design of the study and data collection and approved the version as submitted. KS participated in the conception, design of the study and data collection and approved the version as submitted. Ml participated in the PCB and methlmercury data confirmation. KM participated in the design of the study and performed the statistical analysis. HS conceived of the study, and participated in its design and coordination and helped to draft the manuscript. All authors read and approved the final manuscript.

\section{Competing interest}

The authors declare that they have no competing interest.

\section{Consent for publication}

Not applicable.

\section{Ethics approval and consent to participate}

All procedures of this study were approved by the Medical Ethics Committee of the Tohoku University Graduate School of Medicine. This study was conducted with written informed consent from all subjects.

\section{Publisher's Note}

Springer Nature remains neutral with regard to jurisdictional claims in published maps and institutional affiliations.

\section{Author details}

'Development and Environmental Medicine, Tohoku University Graduate School of Medicine, Sendai, Japan. ${ }^{2}$ Miyagi University of Education, Sendai, Japan. ${ }^{3}$ Faculty of Education, Kochi University, Kochi, Japan. ${ }^{4}$ National Institute for Environmental Studies, Tsukuba, Japan. ${ }^{5}$ Department of Environmental Health Sciences, Akita University Graduate School of Medicine, Akita, Japan. ${ }^{6}$ Tohoku University Graduate School of Medicine, Sendai, Japan. 72-1 Seiryo-machi, Aoba-ku, Sendai, Miyagi 980-8575, Japan.

\section{Received: 21 November 2016 Accepted: 25 January 2017} Published online: 12 April 2017

\section{References}

1. Odland JØ, Nieboer E, Romanova N, Thomassen Y, Lund E. Blood lead and cadmium and birth weight among sub-arctic and arctic populations of Norway and Russia. Acta Obstet Gynecol Scand. 1999;78:852-60.

2. Osman K, Åkesson A, Berglund M, Bremme K, Schütz A, Ask K, et al. Toxic and essential elements in placentas of Swedish women. Clin Biochem. 2000;33:131-8.

3. Srivastava S, Mehrotra PK, Srivastava SP, Tandon I, Siddigui MKJ. Blood lead and zinc in pregnant women and their offspring in intrauterine growth retardation cases. J Anal Toxicol. 2001;25:461-5.

4. Schell LM, Denham M, Stark AD, Parsons PJ, Schulte EE. Growth of infants' length, weight, head and arm circumferences in relation to low levels of blood lead measured serially. Am J Hum Biol. 2009;21:180-7.

5. Gundacker C, Fröhlich S, Graf-Rohrmeister K, Eibenberger B, Jessenig V, Gicic $D$, et al. Perinatal lead and mercury exposure in Austria. Sci Total Environ. 2010:408:5744-9.

6. Zhu M, Fitzgerald EF, Gelberg KH, Lin S, Druschel CM. Maternal low-level lead exposure and fetal growth. Environ Health Perspect. 2010;118:1471-5.

7. Karita K, Sakamoto M, Yoshida M, Tatsuta N, Nakai K, Iwai-Shimada M, et al. Recent epidemiological studies on methylmercury, mercury and selenium. Nihon Eiseigaku Zasshi. 2016;71:236-51.

8. Fein GG, Jacobson JL, Jacobson SW, Schwartz PM, Dowler JK. Prenatal exposure to polychlorinated biphenyls: effects on birth size and gestational age. J Pediatr. 1984;105:315-20.

9. Patandin S, Koopman-Esseboom C, de Ridder MA, Weisglas-Kuperus N, Sauer PJ. Effects of environmental exposure to polychlorinated biphenyls and dioxins on birth size and growth in Dutch children. Pediatr Res. 1998:44:538-45.

10. Rylander L, Strömberg U, Dyremark E, Ostman C, Nilsson-Ehle P, Hagmar L. Polychlorinated biphenyls in blood plasma among Swedish female fish consumers in relation to low birth weight. Am J Epidemiol. 1998;147:493-502.
11. Halldorsson TI, Thorsdottir I, Meltzer HM, Nielsen F, Olsen SF. Linking exposures to polychlorinated biphenyls with fatty fish consumption and reduced fetal growth among Danish pregnant women: a cause for concern? Am J Epidemiol. 2008;168:958-65.

12. Dar E, Kanarek MS, Anderson HA, Sonzogni WC. Fish consumption and reproductive outcomes in Green Bay, Wisconsin. Environ Res. 1992;59:189-201.

13. Vartiainen T, Jaakkola JJK, Saarikoski S, Tuomisto J. Birth weight and sex of children and the correlation to the body burden of PCDDs/PCDFs and PCBs of the mother. Environ Health Perspect. 1998;106:61-6.

14. Gladen BC, Shkiryak-Nyzhnyk ZA, Chyslovska N, Zadorozhnaja TD, Little RE. Persistent organochlorine compounds and birth weight. Ann Epidemiol. 2003;13:151-7.

15. Longnecker MP, Klebanoff MA, Brock JW, Guo X. Maternal levels of polychlorinated biphenyls in relation to preterm and small-for-gestationalage birth. Epidemiology. 2005;16:641-7.

16. Weisskopf MG, Anderson HA, Hanrahan LP, Kanarek MS, Falk CM, Steenport $D M$, et al. Maternal exposure to Great Lakes sport-caught fish and dichlorodiphenyl dichloroethylene, but not polychlorinated biphenyls, is associated with reduced birth weight. Environ Res. 2005;97:149-62.

17. Mendez MA, Plana E, Guexens M, Foradada Morillo CM, Albareda RM, Garcia-Esteban R, et al. Seafood consumption in pregnancy and infant size at birth: results from a prospective Spanish cohort. J Epidemiol Community Health. 2010;64:216-22.

18. Foldspang A, Hansen JC. Dietary intake of methylmercury as a correlate of gestational length and birth weight among newborns in Greenland. Am J Epidemiol. 1999;132:310-7.

19. Ramirez GB, Cruz MCV, Pagulayan O, Ostrea E, Dalisay C. The Tagum Study I: analysis and clinical correlates of mercury in maternal and cord blood, breast milk, meconium, and infants' hair. Pediatrics. 2000;106:774-81.

20. Ramon R, Ballester F, Aguinagalde X, Amurrio A, Vioque J, Lacasaria M, et al. Fish consumption during pregnancy, prenatal mercury exposure, and anthropometric measures at birth in a prospective mother-infant cohort study in Spain. Am J Clin Nutr. 2009;90:1047-55.

21. Drouillet-Pinard P, Huel G, Slama R, Forhan A, Sahuquillo J, Goua V, et al. Prenatal mercury contamination: relationship with maternal seafood consumption during pregnancy and fetal growth in the 'EDEN motherchild' cohort. Br J Nutr. 2010;104:1096-100.

22. Herman HG, Miremberg H, Nini N, Feit H, Schreiber $L$, Bar J, et al. The effects of maternal smoking on pregnancy outcome and placental histopathology lesions. Reprod Toxicol. 2016;65:23-8.

23. Curhan GC, Willett WC, Rimm EB, Spiegelman D, Ascherio AL, Stampfer MJ. Birth weight and adult hypertension, diabetes mellitus, and obesity in US men. Circulation. 1996;94:3246-50.

24. Konishi Y, Kuwabara K, Hori S. Continuous surveillance of organochlorine compounds in human breast milk from 1972 to 1998 in Osaka, Japan. Arch Environ Contam Toxicol. 2001;40:571-8.

25. Bell ML, Samet JM. Air pollution. In: Frunkin H, editor. Environmental health: from global to local. 2nd ed. San Francisco: Wiley; 2010. p. 387-415.

26. Strain JJ, Davidson PW, Bonham MP, Duffy EM, Stokes-Riner A, Thurston SW, et al. Associations of maternal long-chain polyunsaturated fatty acids, methyl mercury, and infant development in the Seychelles Child Development Nutrition Study. Neurotoxicology. 2008;29:776-82.

27. Miyashita C, Sasaki S, Ikeno T, Araki A, Ito S, Kajiwara J, et al. Effects of in utero exposure to polychlorinated biphenyls, methylmercury, and polyunsaturated fatty acids on birth size. Sci Total Environ. 2015;533:256-65.

28. Hertz-Picciotto I, Charies MJ, James RA, Keller JA, Willman E, Teplin S. In utero polychlorinated biphenyl exposures in relation to fetal and early childhood growth. Epidemiology. 2005;16:648-56.

29. Sonneborn D, Park HY, Petrik J, Kocan A, Palkovicova L, Trnovec T, et al. Prenatal polychlorinated biphenyl exposures in eastern Slovakia modify effects of social factors on birthweight. Paediatr Perinatal Epidemiol. 2008; 22:202-13.

30. Suzuki K, Nakai K, Sugawara T, Nakamura T, Ohba T, Shimada M, et al. Neurobehavioral effects of prenatal exposure to methylmercury and PCBs, and seafood intake: neonatal behavioral assessment scale results of Tohoku study of child development. Environ Res. 2010;110:699-704.

31. Tatsuta N, Nakai K, Murata K, Suzuki K, Iwai-Shimada M, Yaginuma-Sakurai K, et al. Prenatal exposures to environmental chemicals and birth order as risk factors for child behavior problems. Environ Res. 2012;114:47-52.

32. Tatsuta N, Nakai K, Murata K, Suzuki K, Iwai-Shimada M, Kurokawa N, et al. Impacts of prenatal exposures to polychlorinated biphenyls, methylmercury 
and lead on intellectual ability of 42-month-old children in Japan. Environ Res. 2014;133:321-6.

33. Tatsuta N, Nakai K, Satoh H, Murata K. Impacts of the Great East Japan earthquake on child's IQ. J Pediatr. 2015:167:745-51.

34. Nakai K, Suzuki K, Oka T, Murata K, Sakamoto M, Okamura K, et al. The Tohoku Study of Child Development: a cohort study of effects of perinatal exposures to methylmercury and environmentally persistent organic pollutants on neurobehavioral development in Japanese children. Tohoku J Exp Med. 2004;202:227-37.

35. Nakamura T, Nakai K, Matsumura T, Suzuki S, Saito Y, Satoh H. Determination of dioxins and polychlorinated biphenyls in breast milk, maternal blood and cord blood from residents of Tohoku, Japan. Sci Total Environ. 2008;394:39-51.

36. Schisterman EF, Whitcomb BW, Louis GM, Louis TA. Lipid adjustment in the analysis of environmental contaminants and human health risks. Environ Health Perspect. 2005;113:854-7.

37. Schaller $\mathrm{KH}$, Angerer J, Drexler $\mathrm{H}$. Quality assurance of biological monitoring in occupational and environmental medicine. J Chromatogr. 2002;778:403-17.

38. Kostyniak PJ, Stinson C, Greizerstein HB, Buck JVG, Mendola P. Relation of Lake Ontario fish consumption, lifetime lactation, and parity to breast milk polychlorobiphenyl and pesticide concentrations. Environ Res. 1999;80: S166-74.

39. Hossain MG, Saw A, Alam R, Ohtsuki F, Kamuarul T. Multiple regression analysis of anthropometric measurements influencing the cephalic index of male Japanese university students. Singapore Med J. 2013:54:516-20.

40. Taylor CM, Tilling K, Golding J, Emond AM. Low level lead exposure and pregnancy outcomes in an observational birth cohort study: dose-response relationships. BMC Res Notes. 2016;9:291.

41. Karmaus W, Zhu X. Maternal concentration of polychlorinated biphenyls and dichlorodiphenyl dichlorethylene and birth weight in Michigan fish eaters: a cohort study. Environ Health. 2004;3:1.

42. Wojtyniak BJ, Rabczenko D, Jönsson BAG, Zvezday V, Pedersen HS, Rylander $L$, et al. Association of maternal serum concentrations of $2,2^{\prime}, 4,4^{\prime} 5,5^{\prime}-$ hexachlorobiphenyl (CB-153) and 1,1-dichloro-2,2-bis (p-chlorophenyl)ethylene ( $p, p^{\prime}$-DDE) levels with birth weight, gestational age and preterm births in Inuit and European populations. Environ Health. 2010;9:56.

43. Verner MA, McDougall R, Glynn A, Andersen ME, Clewell III HJ, Longnecker MP. Is the relationship between prenatal exposure to PCB-153 and decreased birth weight attributable to pharmacokinetics? Environ Health Perspect. 2013;121:1219-24.

44. Yamashita F, Hayashi M. Fetal PCB syndrome: clinical features, intrauterine growth retardation and possible alteration in calcium metabolism. Environ Health Perspect. 1985;59:41-5.

45. Sakamoto M, Chan HM, Domingo JL, Kubota M, Murata K. Changes in body burden of mercury, lead, arsenic, cadmium and selenium in infants during early lactation in comparison with placental transfer. Ecotoxicol Environ Saf. 2012;84:179-84

46. Weihe P, Grandjean P, Jørgensen PJ. Application of hair-mercury analysis to determine the impact of a seafood advisory. Environ Res. 2005:97:201-8.

47. Obi E, Okafor C, Igwebe A, Ebenebe J, Afonne OJ, Ifediata F, et al. Elevated prenatal methylmercury exposure in Nigeria: evidence from maternal and cord blood. Chemosphere. 2015;119:485-9.

48. Sakamoto M, Nakano A, Akagi H. Declining Minamata male birth ratio associated with increased male fetal death due to heavy methylmercury pollution. Environ Res. 2001;87:92-8.

49. Konishi K, Sasaki S, Kato S, Ban S, Washino N, Kajiwara J, et al. Prenata exposure to $\mathrm{PCDDs} / \mathrm{PCDF}$ and dioxin-like $\mathrm{PCBs}$ in relation to birth weight. Environ Res. 2009;109:906-13.

50. Grandjean P, Bjerve KS, Weihe P, Steuerwald U. Birthweight in a fishing community: significance of essential fatty acids and marine food contaminants. Int J Epidemiol. 2001;30:1272-8.

\section{Submit your next manuscript to BioMed Central and we will help you at every step:}

- We accept pre-submission inquiries

- Our selector tool helps you to find the most relevant journal

- We provide round the clock customer support

- Convenient online submission

- Thorough peer review

- Inclusion in PubMed and all major indexing services

- Maximum visibility for your research

Submit your manuscript at www.biomedcentral.com/submit
Biomed Central 